\title{
Disc edge veins of Kraupa: rare exit anomalies of the retinal vein
}

Luiza Barroso, William F Hoyt, Michael Narahara

Neuro-Ophthalmology Unit, Departments of Ophthalmology, Neurological Surgery, and Neurology,

University of California,

San Francisco, California 94143, USA

L Barroso

W F Hoyt

M Narahara

Correspondence to:

William F Hoyt, MD

Department of Neurological

Surgery, $c / 0$ The Editorial

Office, 1360 Ninth Avenue,

Suite 210, San Francisco,

California 94122, USA.

Accepted for publication

12 December 1991
Figure 2 Fluorescein angiograms of the patient in case 1. Upper left: beginning laminar flow in the upper branches of the retinal vein at 17.9 seconds. Upper right: laminar flow in all retinal veins including the main trunk at 18.8 seconds. Lower left: complete fluorescein filling of the retinal veins at $25 \cdot 3$ seconds. Lower right: late venous phase at $162 \cdot 2$ seconds. Note absence of pooling of dye in the choroid around the exit point of the main venous trunk.

\begin{abstract}
Disc edge veins of Kraupa are anomalies of the retinal venous system in which blood flows from the retina through a single venous trunk at or near the edge of the disc instead of at its centre. We report two examples of patients with these anomalies and illustrate the appearance of the anomalies with fundus photographs and a fluorescein angiogram. In one patient the retinal vein exited the eye through the sclera at the margin of the optic disc; in the other it disappeared into the disc tissue near the disc margin.
\end{abstract}

In 1915, Elschnig's assistant at the University Eye Clinic in Prague, Ernst Kraupa, published a drawing and description of a rare anomaly of the retinal venous system in which the main trunk of the retinal vein disappeared into the margin of the optic disc instead of its centre. ' The first and only bilateral occurrence of this anomaly was recorded in $1916 .{ }^{2}$ Kraupa

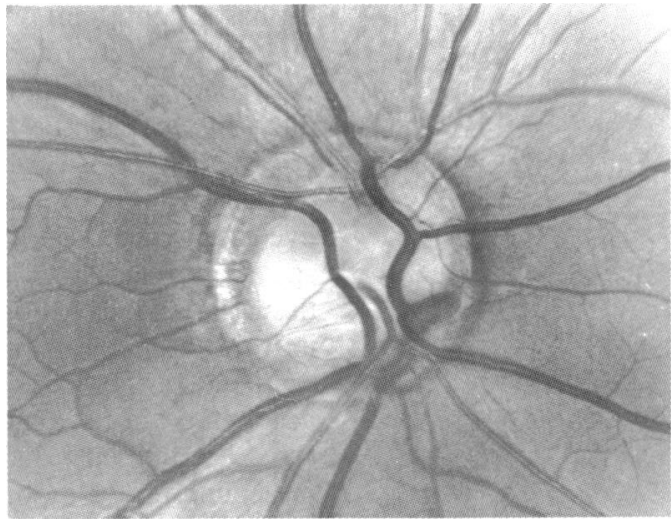

Figure 1 Disc edge vein of Kraupa in the right eye of the patient in case 1 . The main trunk of the central retinal vein enters the bevelled scleral margin of the optic disc at 40 'clock beneath the level of the pigment epithelium and choroid.

added another example in 1924 in an extensive review and classification of arterial and venous anomalies at the optic disc margin. Altogether, we know of only four descriptions of Kraupa's

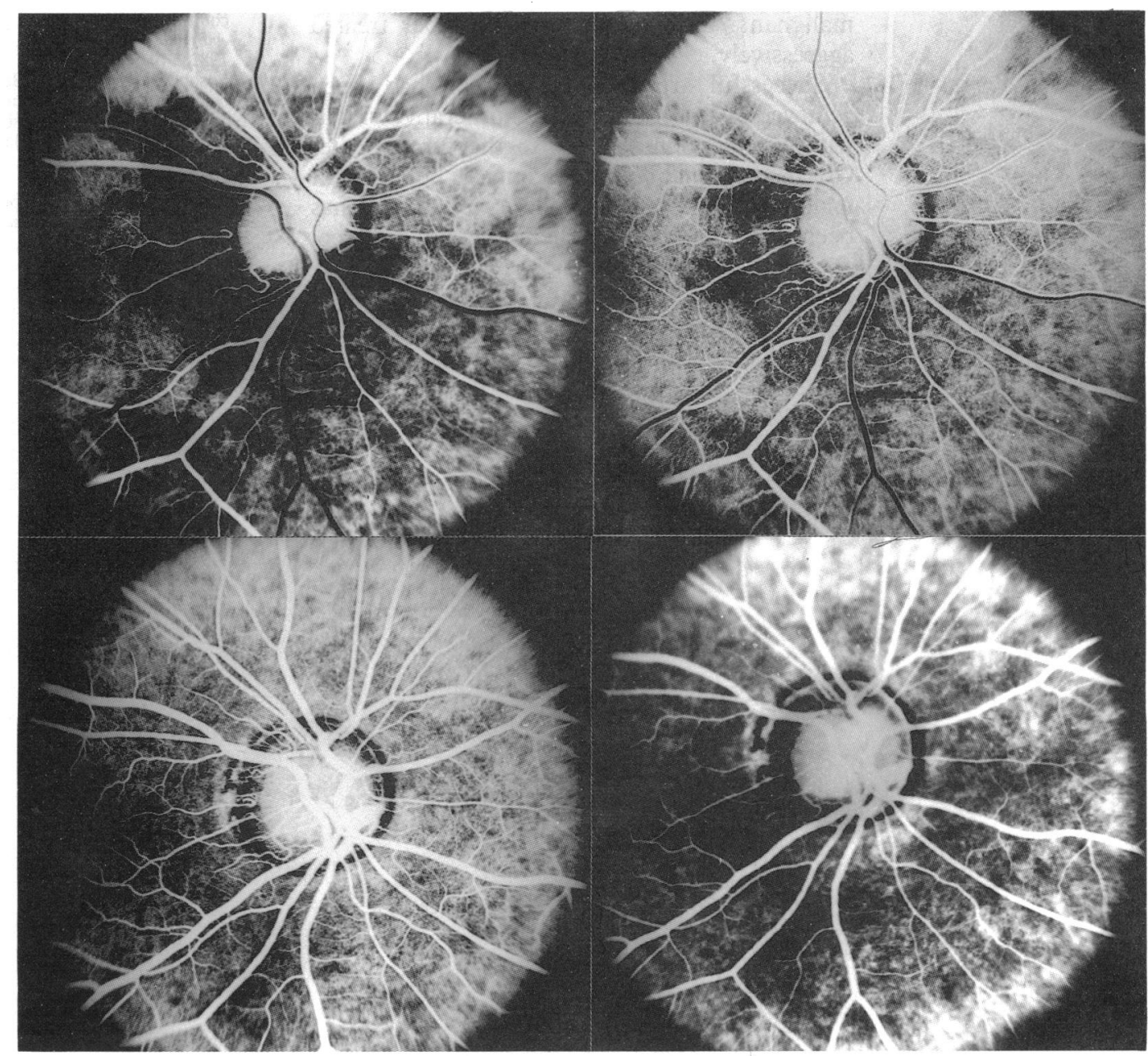


Figure 3 Disc edge vein of Kraupa in the left eye of the patient in case 2 . The main trunk of the central retinal vein directly enters the optic disc at 11 o'clock. The retina is supplied by four arteries with separate exits at the nerve head. The central portion of the optic disc is devoid of arteries, veins, and optic cup.

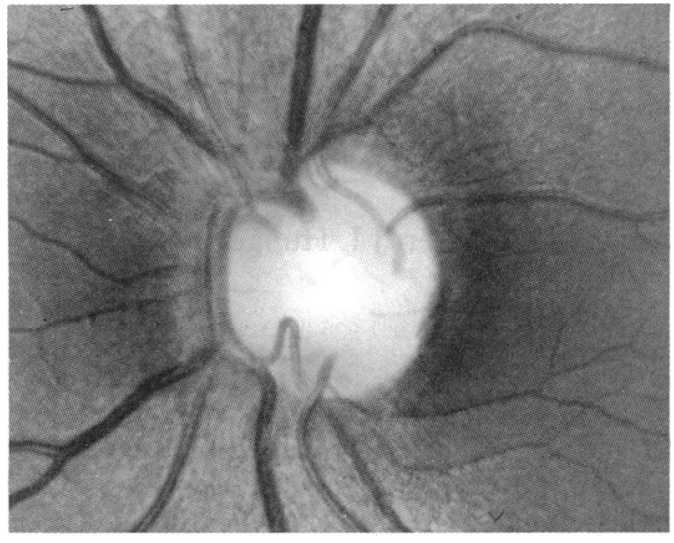

disc edge vein, all occurring before $1949 . .^{1-4}$ This report describes two differing examples of this anomaly, the first to be illustrated with modern fundus photographs and, in one case, fluorescein angiograms.

\section{Case reports}

CASE 1

A 25-year-old man who came to our eye clinic for a routine eye examination had mild myopia, normal corrected visual acuities, and normal visual fields. Both of his optic discs were small in diameter, had a bevelled scleral margin, and were flat without evidence of a physiological cup. The right disc had a striking anomaly of the retinal venous system in which all branches of the retinal vein joined in a common trunk that entered the bevelled disc margin inferonasally at 4 o'clock (Fig 1). Stereoscopic views confirmed that this venous trunk disappeared into the scleral edge beneath the level of the retinal pigment epithelium and choroid. The superior temporal vein crossed the disc surface and joined the inferior temporal vein above the disc margin at 6 o'clock without giving off a branch into the central portion of the disc. The central retinal artery issued from the disc as superior and inferior arterial trunks, which probably came from a single central arterial trunk that was invisible beneath the disc surface.

Fluorescein angiography (Fig 2) showed smooth and progressive laminar flow in the venous branches and the common venous trunk between $17 \cdot 3$ and 22.5 seconds. The venous tree was uniformly opacified with dye at 23.4 seconds. There was no pooling (increased concentration) of dye in the peripapillary choroid near the entrance of the common retinal venous trunk at any time. The dye column in the trunk vessel disappeared from view at the scleral margin. The choroidal filling was at first patchy but became complete between 18 and 25 seconds.

CASE 2

A 35-year-old woman was examined in our unit for evaluation of eye movement abnormalities associated with advanced cerebellar degenerative disease. Her visual acuities and visual fields were normal and she had no significant refractive error. Examination of both ocular fundi showed striking anomalies of retinal veins and arteries at the optic discs. The discs were slightly smaller than normal in diameter, had a flat cupless surface, and had no major vessels entering or leaving the central region.

The right disc had four arteries with separate exits at the nerve head, each artery supplying one of the quadrants of the retina. No central retinal artery was seen. The retinal veins formed superior and inferior venous trunks that converged above and below the disc and then entered the disc tissue, probably joining as a central venous trunk beneath the disc surface. The left disc (Fig 3) also had four arteries with separate exits at the nerve head, each supplying a retinal quadrant, and there was no central retinal artery. All retinal venous branches converged into a common venous trunk that ran upward over the nasal disc margin and entered the disc tissue inside the disc margin at 11 o'clock.

\section{Discussion}

Our cases conform closely with Kraupa's descriptions of disc edge veins draining the retina through a single trunk (Optikusrandvene). The veins in our two cases differ from each other in the way they exit the eye. In case 1 the vein enters the wall of the scleral canal, whereas in case 2 it enters the nerve itself. Our examination of published drawings of disc edge veins showed similar differences. Kraupa's first case ${ }^{1}$ and von Herrenschwand's bilateral case ${ }^{2}$ resemble our case 1; Kraupa's second case ${ }^{3}$ and Oxilia's case ${ }^{4}$ resemble our case 2 .

There is no published report of a histologically studied disc edge vein. Therefore, the various paths taken by such veins after they disappear from ophthalmoscopic view and pass into the orbital venous plexus remain a matter for speculation. Our two cases show clearly that disc edge veins can take at least two routes out of the eye.

Elschnig ${ }^{5}$ stressed the extreme rarity of disc margin arteries occurring in conjunction with disc margin veins. Our case 2 is noteworthy in this regard. It is an example in which multiple disc margin arteries supplying all quadrants of the retina were present in a patient who also had a Kraupa's disc edge vein. Lawford ${ }^{6}$ illustrated a similar anomaly in 1895 .

\footnotetext{
1 Kraupa E. Die Anastomosen an Papillen-und Netzhautvenen. Arch Augenheilkd 1915; 78: 182-207.

2 von Herrenschwand F. Angeborene beiderseitige gleichgerich tete Optiko-Ziliarvenen. Klin Monatsbl Augenheilkd 1916; 56: 504-8.

3 Kraupa E. Beiträge zur Morphologie des Augenhintergrundes IV. Optikoziliare Arterien, Optikusrandvenen und optikochorioideale Venen. Klin Monatsbl Augenheilkd 1924; 72 $724-40$.

4 Oxilia E. Anomalie congenite del fondo dell'occhio: vene marginali del nervo ottico e reliquati jaloidea. Ann Ottalmol Clin Ocul 1949; 75: 20-9.

5 Elschnig A. Cilioretinale Gefässe. A. von Graefe's Arch Ophthalmol 1897; 44: 144-71.

6 Lawford JB. Unusual arrangement of retinal vessels. Trans
} Ophthalmol Soc UK 1895; 15: 195. 